\title{
XLV. On delicate calorimetric thermometers
}

\section{Spencer Umfreville Pickering M.A.}

To cite this article: Spencer Umfreville Pickering M.A. (1886) XLV. On delicate calorimetric thermometers, Philosophical Magazine Series 5, 21:131, 330-342, DOI: 10.1080/14786448608627854

To link to this article: http://dx.doi.org/10.1080/14786448608627854

$$
\text { 曲 Published online: } 08 \text { Jun } 2010 .
$$

Submit your article to this journal $\square$
Џll Article views: 2 
error, therefore, in experiments where one thermometer is used will have to be increased by half this amount, thus becoming \pm 18.86 cal. This number, then, represents the probable divergence from the truth of any one experiment; and, from the manner in which the various thermometers were standardized (by comparison with each other), this error will probably be as great when two experiments performed at different temperatures are compared, whether they were performed with the same or with different instruments.

Perhaps, for the purpose of determining this probable error, the calculations ought to be based on the difference between duplicate experiments performed not on the same day, in which case the error would be somewhat larger. I have not done so, however, chiefly owing to uncertainty in the number given for this quantity (see above). Many causes also which tend to increase the difference when the experiments are not performed consecutively might not apply in general. Amongst these I may mention the very hygroscopic nature of many of the salts taken, where a difference in the state of moisture of the atmosphere would affect the extent to which traces of water were absorbed during their exposure while being transferred to the weighing-tubes: these substances, again, were often kept in sealed tubes containing sufficient for two or three determinations only, and the contents of the various tubes may not have been dried to precisely the same degree.

XLV. On Delicate Calorimetric Thermometers. By SPENCER Umfrevilue Piokerlang, M.A., Professor of Chemistry at Bedford College*.

T $\mathrm{N}$ the foregoing communication it has been shown that the average error of a determination of the heat of dissolution of a salt in $400 \mathrm{H}_{2} \mathrm{O}$ amounts to $\pm 18.86 \mathrm{cal}$.; but this is only an average, and it must not be overlooked that the error in some cases may exceed this very considerably. It is not uncommon to find a difference of 40 or 50 cal. between two duplicate experiments (although the average error in such cases is only $\pm 13.3 \mathrm{cal}$.), and a proportionately larger error must therefore be expected occasionally in the comparison of two experiments at different temperatures.

The determinations from which these conclusions were draw'n consisted of a series of experriments with various salts at temperatures ranging from $1^{\circ}$ to $26^{\circ} \mathrm{C}$., where it was imperative that the greatest possible accuracy should be attained, and also that the experiments at the different temperatures should all be strictly comparable with each other. 'I'he ther-

* Communicated by the Physical Society : read February 13, 1886. 
mometers employed had a range of $15^{\circ} \mathrm{C}$., and a total length of 600 millim.; it was therefore impossible to increase their length sufficiently to make one instrument embrace the whole range of $25^{\circ} \mathrm{C}$, and any increase in the delicacy (by increasing the size of the bulb) would have involved a diminution in their range, so that more than two instruments would have been required, while in such experiments it is obviously of the greatest importance that as few instruments as possible should be used.

With a view to overcoming these difficulties the following expedient was adopted, whereby the delicacy of the instrument was increased six- or sevenfold, its range was made to embrace that of all temperatures at which a mercurial thermometer can be used, and its registration was rendered (for these purposes) practically independent of calibration and standardization error.

The principle on which it was worked consisted in removing a portion of the mercury, by the applieation of heat, into the upper chamber, and thus adjusting any particular point in the instrument so as to register any required temperature. Experiments on the same substance at different temperatures were thus made absolutely comparable, exactly the same portion of the scale being used in each case.

The zero point of the thermometer being thus altered for each experiment, the actual temperature in degrees Centigrade which it registers will not be known with any great degree of accuracy; but this is not necessary in calorimetric work: the heat of chemical combination is affected to such a small extent by temperature, that an error of $05^{\circ}$ or $\cdot 1^{\circ} \mathrm{C}$. in this will be unimportant; and by a rough comparison of the thermometer with some standard instrument after each adjustment of the mercury, the temperature which it registers can be easily ascertained within $.01^{\circ}$ or ${ }^{\circ} 02^{\circ} \mathrm{C}$.

This thermometer (No. 62839) possessed a total length of 746 millim., of which 565 millim. constituted the divided portion of the stem, each division being 1 millim., and ten such divisions being termed 1 degree. The bulb measured 72 millim. in length, and was made out of glass cylinder instead of being blown, a detail which is rarely attended to in the construction of delicate thermometers, but one which is most important in giving the bulb greater stability and greater uniformity of action. 'The weight of mercury in the bulb was $36^{\circ} \cdot 23^{*}$ grams,

* In the other instruments, with a range of $15^{\circ} \mathrm{C}$, the weight of mercury varied between $13 \cdot 6$ and $15 \cdot 6$ grams; the bore of the tube of No. 62839 would be considerably more than twice as fine as in these. Fuller details respecting these instruments will be found in the Phil. Mag. March $1886^{3}$. 
and the total range of the instrument only $3^{\circ} \cdot 4 \mathrm{C}$., giving 166 millim. to each degree $\mathrm{C}$.; one estimation figure ( .05 millim.) would therefore represent $\cdot 0003^{\circ} \mathrm{C}$.

In using this thermometer it is first suspended in the calorimeter containing water at a temperature a certain known degree above that at which the experiments are to be made; a very small flame is then applied to a point just below the upper chamber (which in such instruments must be of considerable size), by which means the column of mercury is broken off at the part thus heated, and the separated portion remains in the upper chamber, the tube being much too fine to permit of it being shaken down again. After cooling it is put into a bath at the required temperature, and compared with some standard instrument. In this way the registration of the thermometer can be adjusted to any required temperature within $05^{\circ} \mathrm{C}$ : without the least difficulty; but greater accuracy could be obtained if necessary.

This thermometer was employed in a large number of experiments, and the general results, as will be shown below, proved to be satisfactory. But it possessed one serious imperfection, or, more properly speaking, its delicacy brought into light an imperfection which must be inherent, although it has hitherto been unnoticed in all mercurial thermometers.

As is well known, the bulb of a thermometer does not expand regularly when heated ; "en effet," to quote Berthelot's words, "la marche de l'instrument est intermittent, c'est-àdire que le niveau n'est souvent atteint qu'après une série de petites oscillations" *. To obtain a state of equilibrium the thermometer must be tapped on the top with the finger, or some such means adopted to overcome the inertia of the bulb before each reading. The larger the bulb and the finer the bore of the tube, the more apparent dues this inertia become : with instruments such as the less delicate ones here mentioned a dozen or less taps are sufficient to overcome it, but with No. 62839 it was found that continuous tapping for two or

* Méc. Chim. i. p. 178. It is curious to note that even while Berthelot is warning his readers against this source of error he appears to have fallen into it himself. On p. 163 he gives the results of a comparison of two thermometers placed in a bath of water, the temperature of which was rising, and read simultaneously at intervals of ten minutes; from this and other closely concordant comparisons he finds 6.702 degrees of the one instrument are equivalent to 14.827 of the other; but, on looking more closely at each reading, it will be found that

(1) a rise of 0.9 in the one corresponds to a rise of $i \cdot 1$ in the other.

\begin{tabular}{|c|c|c|c|c|c|}
\hline 2) & 0.7 & 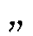 & 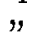 & $"$ & $2 \cdot 2$ \\
\hline (3) & 06 & $"$ & $"$ & $"$ & 1.5 \\
\hline (4) & $1 \cdot 1$ & $"$ & " & $"$ & 0.9 \\
\hline$"$ & $1 \cdot 2$ & $"$ & $"$ & " & $1 \cdot 1$ \\
\hline
\end{tabular}


three minutes was absolutely necessary. The extent to which error from this source may accumulate may be drawn from the fact that this instrument, when the mercury is rising to the temperature of the bath in which it is placed, will register 6 millim. lower than when falling to the same temperature, however long it be left in the bath, if it be not tapped (the temperature of the bath in this case was such that the mercury stood at about the middle point of the stem). Again, it was found, by means of a series of experiments in which the height of the column was read when the instrument was inclined at different angles, that with thermometer 55082, which possessed a blown bulb containing $15 \cdot 6$ grams of mercury, a difference of 6.6 millim. in the reading was made when the instrument was placed horizontally instead of vertically; making due allowance for the greater size of the bulb and greater fineness of the bore in 62839 , this latter instrument would probably exhibit a difference of at least ten times this quantity under similar treatment. This will give some adequate idea of how great an effect the expansion of the bulb under pressure may have on the reading.

Now, besides the inertia of the bulb, which may be overcome by a sufficient amount of tapping, there appears to be another and more serious imperfection, dne to what may be termed a permanent alteration in size, as opposed to the other, which may be called temporary, and one which no amount of tapping will overcome. It would seem that the bulb of this, and every thermometer, has two different shapes, one when the column is rising, the other when it is falling. The following simple experiments will serve to show this.

The thermometer being suspended in the calorimeter full of water, the contents of this were heated or cooled slightly, and the rate of cooling (or heating) determined during consecutive intervals.

In the first column the time is entered, in the second the reading of the instrument, and in the third the rate of cooling or heating.

A. Experiments in which a rate of heating was determined. I.

Time. Reading (arbitrary). Rate.

$0-i$

Hot water added.

$\begin{array}{rl}1 \text { min. } & 19 \cdot 96 \\ 4 \%, & 20 \cdot 07 \\ 7 \% & 20 \cdot 165 \\ 10 " & 20 \cdot 245 \\ 13 " & 20 \cdot 38 \\ 16 " & 20 \cdot 47\end{array}$

$\left.\begin{array}{l}\cdot 11 \\ \cdot 095 \\ \cdot 08 \\ \cdot 135 \\ \cdot 09\end{array}\right\}$ mean $=\cdot 10$ 
II.

Time.

Reading.

Rate.

$0 \quad-5$

Hot water added.

$\left.\begin{array}{rll}2 \text { min. } & 20 \cdot 685 & \cdot 075 \\ 5 \% & 20 \cdot 76 & .095 \\ 8 \% & 20 \cdot 855 & .085 \\ 11 " & 20.94 & .09\end{array}\right\}$ mean 09.

In this case the rate of heating is constant from the very beginning: during the first three minutes it differs from the mean of the other intervals by $+\cdot 01$ in Exp. 1 and by - $\cdot 015$ in Exp. 2, both of these quantities being well within the limits of experimental error.

\begin{tabular}{ccc} 
& \multicolumn{2}{c}{ III. } \\
Time. & Reading. & Rate. \\
0 & 54 &
\end{tabular}

Cold water added.

$\left.\begin{array}{rll}2 \text { min. } & 20.555 & \cdot 005 \\ 5 \% & 20.56 & .09 \\ 8 \% & 20 \cdot 65 & .085 \\ 11 \% & 20 \cdot 735 & .105\end{array}\right\}$ mean $\cdot 093$.

\section{IV.}

Time.

0

Reading.
54

Rate.

Cold water added.

$\left.\begin{array}{rll}2 \text { min. } & 19 \cdot 45 & .015 \\ 5 \% & 19 \cdot 465 & .09 \\ 8 \% & 19 \cdot 555 & .09 \\ 11 " & 19 \cdot 645 & \cdot 13 \\ 14 \% & 19 \cdot 775 & \end{array}\right\}$ mean $\cdot 103$.

In these two experiments, however, this is not so; the rate of heating (as registered) during the first interval is almost nil, in eaeh case exactly 088 less than the mean deduced from the other intervals. Thus, when the column of mercury rises to any temperature it will go on rising regularly afterwards, indicating the rate of heating correctly, but when it falls to that temperature a certain time elapses before it will begin to rise afterwards; although the mercury must be expanding during this interval, the column is stationary, and therefore the bulb must be expanding, and assuming a new form. 
The following experiments are complementary to the preceding ones and illustrate the same fact.

B. Experiments in which a rate of cooling was measured.

Time.

0

Cold water added.

3 min.

6 "

9 "

12 ,

$15 \%$

Time.

0

Cold water added.

$\begin{array}{rll}3 \text { min. } & 22 \cdot 21 \\ 6 ", & 21 \cdot 84 \\ 9 " & 21 \cdot 48 \\ 12 ", & 21 \cdot 155 \\ 15 ", & 20 \cdot 815\end{array}$

53
I.

Reading. Rate.

55

$22 \cdot 16$

$21 \cdot 76$

$21 \cdot 41$

$20 \cdot 99$

$20 \cdot 59$

II.

Rate. $\cdot 41$

$\cdot 34$

$\cdot 42\}$ mean $\cdot 39$.

The difference between the rate of cooling measured during the first interval and that during the remaining ones being +.02 in the one experiment, and +.028 in the other, $i . e$. practically nil.

$\left.\begin{array}{ccl}\begin{array}{c}\text { Reading. } \\ \text { Time. }\end{array} & \text { Rate. } \\ 0 & 0 & \\ \text { Hot water added. } & \circ & \\ 2 \text { min. } & 20 \cdot 65 & \cdot 20 \\ 5 \% & 20 \cdot 45 & \cdot 36 \\ 8 \% & 20 \cdot 09 & \cdot 30 \\ 11 \% \text { mean } \cdot 34 . \\ 14 " & 19 \cdot 79 & \cdot 37\end{array}\right\}$


The difference between the first and remaining intervals being $-\cdot 14$ and $-\cdot 18$ in the two experiments. Thus whichever be the direction of the motion of the mercury it will continue in that direction, giving correct results, but, if the direction be changed, an interval elapses before the motion becomes apparent, and a considerable error will be introduced.

The above are but typical experiments out of a large number performed, and all of which gave the same results; indeed, every determination of the heat of dissolution of a salt afforded a fresh exemplification of the fact.

Of course the alteration in the size of the bulb will invalidate any experiment unless its effect be connteracted. This was always done in every experiment by taking care that, if a rate of cooling was to be measured after the salt had beon dissolved, the liquid should be cooling also before its introduction, and vice verssia the motion of the mercury, and therefore the shape of the bulb, being the same at the beginning and end of the experiment, no error would occur. In such an experiment, where for instance a rate of cooling obtained, and the salt dissolved with absorption of heat, no period of inertia in the column would occur; but if the salt dissolved with evolution of heat, two such periods would occur, and, though this would not affect the accuracy of the results, a certain time would elapse before the apparent rate of cooling became constant, extending often to three intervals of 3 or 5 minutes each (for the whole of these intervals cannot be spent in tapping the thermometer as in the experiments quoted above, but are chiefly occupied in reproducing the actions performed in effecting the dissolntion of the salt), thus creating a serious increase in the duration of an experiment. This was obviated by removing the thermometer from the calorimeter, touching the bulb with some warm object, when, on replacing it, the column fell to the temperature of the calorimeter, and proceeded to give the rate of cooling at once; where a rate of heating was to be determined, the thermometer was cooled (by evaporation from the surface) instead of heated. As a few millim. rise or fall are sufficient for the purpose, the heating or cooling of the contents of the calorimeter in such an operation is quite negligible*.

The change of size in the bulb, as deduced from the experiments already quoted, is, perhaps, somewhat exaggerated, owing to an under-estimation at the time of the amount of

* The water-equivalent of the immersed portion of this thermometer was 2.09 grams, that of the calorimeter and cortents about 610 grams. $A$ heating of the former sufficient to produce a rise of $5 \mathrm{~mm}$. wonld raise the temperature of the latter only $0.0 \mathrm{CO} 1^{\circ} \mathrm{C}$. 
tapping which was necessary to overcome the temporary inertia of the bulb. The following, even more simple, experiments are free from such an error, and bring to light other fucts concerning this phenomenon.

The method of procedure here consisted in suspending the thermometer in a calorimeter containing a much larger volume of water than the one generally used, taking the instrument out, heating and cooling it alternately, when, on its being replaced, readings of the same temperature were obtained, the column having fallen or risen to that temperature respectively.

As it was found to be impossible to keep the temperature of the bath constant during the requisite time, any obsorved reading, say when the column was rising to the temperature, was compared with a theoretical reading consisting of the mean of the previous and subsequent readings, both of which were obtained when the column was falling to the temperature. The differences here quoted will represent the total difference between the readings with rising and falling columns. After the thermometer had been replaced in the bath, it was tapped continuously and read at intervals of one minute till it became quite stationary; between five and seven such readings were made in the series here given, although it will be necessary to quote the final reading only in each case. An interval of about 8 minutes elapsed between these final readings, all the intervals in each separate series being exactly equal.

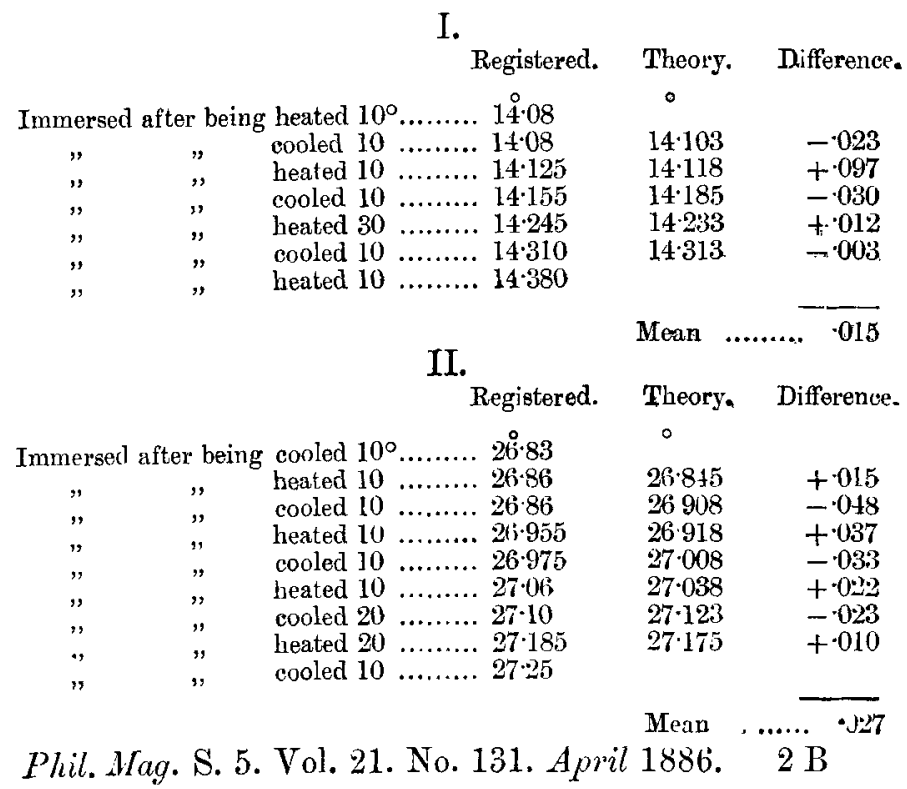




\begin{tabular}{|c|c|c|c|c|c|}
\hline \multicolumn{6}{|c|}{ III. } \\
\hline \multirow{2}{*}{\multicolumn{4}{|c|}{ Immersed after being heated $10^{\circ} \ldots \ldots \ldots 45845$}} & Theory. & Difference. \\
\hline & & & & & \\
\hline ", & , & cooled 10 & $\ldots 45 \cdot 755$ & $45 \cdot 804$ & -.049 \\
\hline ", & " & heated 10 & $\ldots \ldots 45763$ & 45718 & +045 \\
\hline ", & $"$ & cooled 10 & $\ldots \ldots \ldots 45680$ & 45.717 & -.063 \\
\hline ", & $"$ & beated 10 & ........ 45.670 & 45643 & +.027 \\
\hline$"$ & $"$ & cooled 10 & $\ldots \ldots \ldots, 45605$ & $45 \cdot 655$ & -.045 \\
\hline ", & , & heated 10 & ........ $45 \cdot 640$ & 45.595 & $+\cdot 045$ \\
\hline ", & " & cooled 10 & $\ldots \ldots \ldots, 45585$ & $45 \cdot 635$ & -.050 \\
\hline$"$ & $"$ & heated 10 & .... 45630 & & \\
\hline & & & & Mean & $\ldots \cdot 046$ \\
\hline
\end{tabular}

Without exception, therefore, a reading when the thermometer is falling to a given temperature is higher than when it is rising to this same temperature, and the difference between these two readings appears to be independent of the extent of the foregoing fall or rise; a fact which will be shown more clearly in a series of similar experiments with another thermometer to be quoted below. The difference in the two readings, however, is considerably influenced by the position of the mercury in the stem ; from these experiments it would appear to be directly proportional to the height of the column, the total difference in each case being 1000 of this height.

Although this difference is very appreciable, it must be remembered that it corresponds to a difference of very small dimensions in the capacity of the bulb. The $0^{\circ} .015$ measured in the first series is equivalent to $0^{\circ} .0009 \mathrm{C}$., and represents but 0.0000004 c.c., or but little over one millionth part of the total capacity of the bulb (2.64 c.c.), a quantity so small that there is no wonder in its having hitherto escaped observation. The considerable force necessary to push a column of mercury tbrough a long very fine tube is, I should say, quite sufficient to account for this expansion of the bulb; it is well illustrated by the fact that a quick fall of but a small amount canses the mercury to separate at the neck of the bulb.

The question now arises whether this instrument, possessing such serious imperfections, is really workable, or whether we have not pushed thermometric delicacy beyond the limits compatible with accuracy.

The various determinations of the heat of dissolution of salts which were made with this thermometer give the means of answering this question.

As shown in the previous communication, $\pm 13 \cdot 3$ cal. is the average error of each experiment when compared with a duplicate one performed under the same conditions; of this $7.59 \mathrm{cal}$. are error due to manipulation and $5 \cdot 71 \mathrm{cal}$. to error of reading. The manipulation-error will be independent of 
the thermometer employed, but the reading-error will be smaller in direct proportion to the delicacy of the instrument. As an estimation-figure with No. 62839 represents about $\frac{1}{6 \cdot 4}$ of what it does in the case of the instruments to which these numbers refer, the reading-error with it ought to be only $\frac{5 \cdot 71}{6 \cdot 4}$, or about 9 cal., giving a total error for each experiment of $\pm(\cdot 9+7 \cdot 59=) 8 \cdot 49$.

Now the average difference of two duplicate experiments with this thermometer was found to be $14 \cdot 84$ cal. (deduced from 38 experiments), giving an error of only $\pm 7 \cdot 42 *$ cal. for each experiment, a quantity even smaller than that which would have been anticipated, proving conclusively that such an instrument can be worked with just as much certainty as the less delicate ones. The fact that the total error here is even less than the manipulation-error alone in the other experiments is due to greater care being taken in manipulation, a larger number of intervals being allowed for the determination of the rate of cooling. It must be remembered, however, that this diminution of the difference between two duplicate experiments by no means represents the total advantages accruing from the use of this thermometer, for, the same portion of the instrument being used for experiments with the same substance at all the different temperatures, these will be on the same footing as duplicate experiments themselves. We shall, therefore, have to make no addition to this error when comparing different experiments in a series, and we thus get rid at once of the additional error of \pm 5.56 cal, which had to be admitted with the other instruments $\dagger$.

The extra time required for experiments with such an instrument is considerable; the determination itself occupies two or three times as long as with an ordinary thermometer, and the preliminary adjustment of the mercury $\ddagger$ and the

* I am probably very much overstating the error here; this number is deduced from all the experiments in which this thermometer was used. Several of these were performed before the peculiarities of the instrument were thoroughly known, and contained known sources of error; eliminating these, the averige error of the remaining experiments (24 in number) is only +3.33 cal., a surprisingly small quantity.

$\dagger$ From what has been mentioned in the Phil. Mag. March 1886 as to the elror of standardizing this thermometer, the divergence of any measurement from the absolute value will probably not be more than $.00045^{\circ} \mathrm{C}$. for each degree $\mathrm{C}$. measured, or $\pm 3-4$ cal.

I In one instrument which I possess a small particle of dust has become fixed in the tube just below the upper chamber, the result of which is that the column of mercury, whenever it has passed a few millimetres beyond this point, breaks off there and shoots up into the upper chamber. If it were possible to introduce such an obstacle at will, the time expended in separating the mercury by heat, and the danger thereby incurred, would be obviated. I am not without hopes of succeding in effecting this. 
comparison with a standard occupies the greater part of an hour. It is possible to do three determinations at different temperatures with it in a day; but this means a very hard day's work, and could only be effected after much practice.

Although the results obtained with this thermometer may appear satisfactory as measured by the average error, they still leave much to be desired. It is impossible to feel absolute confidence in an instrument which possesses such serious imperfections; and, apart from this, I was desirous of investigating the matter further for its own sake, and producing an instrument in which delicacy did not involve the sacrifice even of convenience.

It occurred to me that the substitution of a double bulb for the single bulb of No. 62839 would probably result in a considerable increase in strength under pressure. Such an instrument, therefore, I had constructed. Considerable difficulty was met with in boiling the mercury in a double bulb thoroughly, but this was overcome in a masterful manner, while at the same time the other parts of the instrument were so perfect that $I$ believe it is the finest thermometer of its kind ever constructed, in this country at any rate. The stem was of the required stoutness, and the bore, while being flat, was well rounded at the edges, thus exposing no crevices into which the mercury would find it difficult to enter, as is usually the case with flat bores, and as was so with No. 62839. The length of each bulb of this instrument, No. 63616 , was $55 \mathrm{~mm}$., the total weight of mercury in them being 30.5 grams, considerably less therefore than in the other thermometer and less than double that in the bulbs of some of the less delicate thermometers. The scale was rather less open than in 62839 , the total range of $60 \mathrm{~cm}$, representing $3^{\circ} .85 \mathrm{C}$., or $154.3 \mathrm{~mm}$. to each degree, one estimation-figure representing therefore $30 \overline{0} \overline{0}^{\circ}$.

The results of two series of experiments with this instrument similar to those with 62839 , last described, gave the following results :-

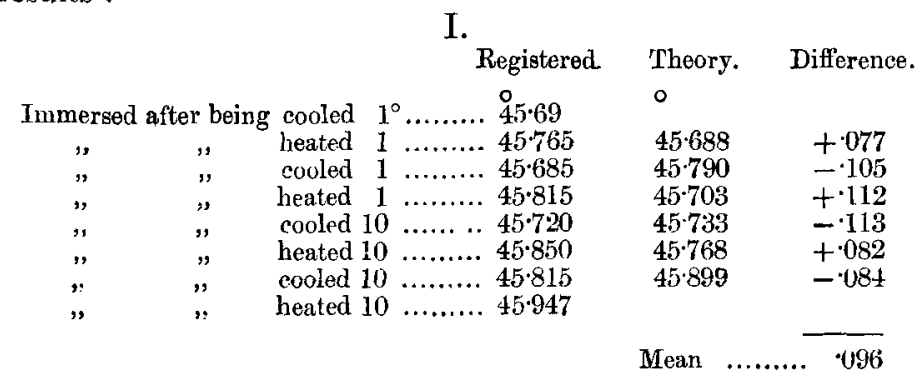




\begin{tabular}{|c|c|c|c|c|c|}
\hline \multirow{2}{*}{\multicolumn{3}{|c|}{ Immersed after being heated $10^{\circ}$}} & $\begin{array}{l}\text { II. } \\
\text { Registered. }\end{array}$ & Theory. & \multirow[t]{2}{*}{ Difference } \\
\hline & & & & & \\
\hline ", & " & cooled 10 & $\ldots \ldots \ldots, 13 \cdot 95$ & $14 \cdot 00$ & -.05 \\
\hline$"$ & ", & heated 10 & $\ldots \ldots \ldots \ldots 11 \cdot 015$ & $13 \cdot 93$ & +085 \\
\hline , & $"$ & cooled 10 & ........ 1391 & 14029 & $-\cdot 119$ \\
\hline$"$ & $"$ & heated 10 & $\ldots \ldots \ldots .14043$ & $13 \cdot 933$ & $+\cdot 110$ \\
\hline$"$ & $"$ & cooled 10 & ........ 13955 & $14 \cdot 044$ & $-\cdot 089$ \\
\hline$"$ & $"$ & heated 10 & ......... 14.045 & & \\
\hline & & & & Lean & .. $\quad 091$ \\
\hline
\end{tabular}

Thus, contrary to expectation, this instrument not only shows a difference in reading when the column is rising or falling to any temperature, but that difference is even greater, and considerably so, than with No. 62839. This is certainly remarkable, and tends to show that a full explanation of this difference has not yet been obtained, for the double bulb would undoubtedly possess a greater rigidity than the single bulb of the other instrument; although the combined length of the two bulbs is 110 millim. as opposed to 72 millim., the diameter of the tubing of which they were made was considerably less, 4.83 millim. instead of 6.86 millim. (internal measurements), and the wall of the tubing also was considerably stouter, 0.76 millim. instead of 0.635 millim., and a small improvement in these last two items would cause a very considerable increase in the rigidity. Another peculiarity in this instrument is that the difference in the readings is independent of the height of the column of mercury; or at any rate very nearly so.

Series I. of the above experiments affords good proof that the difference in readings is independent of the distance through which the column has fallen or risen; the mean difference of the first three numbers in the last column being $\cdot 098$, and that of the last three $\cdot 093$; numbers practically identical, although the fall or rise was 1 degree in the former, and 10 degrees in the latter.

Although this difference, due to what I have termed the permanent alteration in the size of the bulb, is greater with 63616 than with 62839 , it is otherwise with the temporary alteration. An experiment similar to the above, but the tapping of the instrument being omitted, gave a difference of $0^{0.23}$ in the mercury standing at $45 \cdot 8$, whereas with 62839 it amounted to $0^{\circ} \cdot 6\left(\right.$ at $\left.27^{\circ}\right)$; these numbers representing the sum of the permanent and temporary alterations, the latter only will be represented by $(\cdot 23-\cdot 09 t=) 0^{\circ} \cdot 13$, and $(\cdot(j-\cdot 027=)$ $0^{\circ} .57$ in the two instruments respectively. This tends to confirm an opinion expressed by Mr. Casella, that a considerable 
portion of this temporary alteration is due, not to the bulb, but to the mercury not entirely filing the bore of tube of its own accord, owing to the extreme flatness of this latter at the edges. The tube of which 63616 was made presented no such imperfections. However, neither the permanent nor temporary difference can be in any degree attributed to the action of the tube in this latter instrument, but is wholly due to the bulb itself; for the thermometer was first made up with a small bulb*, containing only 3 grams of mercury, in which state it showed no difference whatever in the readings obtained under different conditions, with or without tapping. The comparative smallness of this temporary alteration in the case of 63616 renders this instrument far more convenient and satisfactory than the otber. Instead of requiring two or three minutes continuous tapping in order to obtain a correct reading, less than one minute is sufficient, and this must very materially increase accuracy in calorimetric determinations. I have not as yet used this thermometer in a sufficient number of experiments to ascertain the experimental error with it; but the uniformity of its action and the increased concordance of the rate of cooling registered in successive intervals, leads me to feel confident that the error with it will be considerably less than with 62839 .

From what has already been said as to the smallness of the reading-error in this instrument, it may be stated that we have pushed thermometric delicacy quite as far as is desirable with regard to calorimetric work, and that to produce a further degree of accuracy in this branch of study, the methods employed, and not the thermometers, must be improved.

In conclusion, I wish to take this opportunity of expressing my warmest thanks to $\mathrm{Mr}$. Casella and to his assistants for the scientific interest which they have shown in this investigation, and the ungrudging manner in which they have spared no pains to help me in attaining my object.

* Where the bulb is to contain as much as 20 or 30 grams of mercury, it is well to have the instrument made up temporarily with a small bulb, for the purpose of calibration, as with fine tubes some rough handling is often necessary to pass a short thread of mereury along them.

It would appear that 30 grams of mercury is not an uncommon amount in the instruments used by Berthelot (Méc. Chim. i. 165), although they are far less delicate than those described in the present communication. He even refers to thermometers containing 250 grams! (p. 156). 